\title{
Labeled lines meet and talk: population coding of somatic sensations
}

\author{
Qiufu Ma
}

Dana-Farber Cancer Institute and Department of Neurobiology, Harvard Medical School, Boston, Massachusetts, USA.

\begin{abstract}
The somatic sensory system responds to stimuli of distinct modalities, including touch, pain, itch, and temperature sensitivity. In the past century, great progress has been made in understanding the coding of these sensory modalities. From this work, two major features have emerged. First, there are specific neuronal circuits or labeled lines transmitting specific sensory information from the skin to the brain. Second, the generation of specific sensations often involves crosstalk among distinct labeled lines. These features suggest that population coding is the mechanism underlying somatic sensation.
\end{abstract}

\section{Introduction}

There is a long debate about how somatic sensations, including touch, pain, itch, and temperature sensitivity, are encoded by the nervous system. Major competing views are specificity theory and pattern theory (1-5). The specificity theory suggests that each sensory modality is processed along a fixed, direct-line communication system from the skin to the brain. The existence of such specific labeled lines was suggested first by Blix, Goldscheider, and Donaldson from 1882 to 1885 and later by von Frey (reviewed in refs. 4 and 6). They found that there are specific spots in the human skin whose activation correlates with a specific sensation: cool, warm, touch, pain, or itch. Electrophysiological recordings then demonstrated the existence of primary sensory fibers and spinal relay neurons that respond to specific stimuli, such as cold, warm, pruritic, and/or noxious stimuli (4, 5, 7-11). Modern molecular, genetic, and behavioral studies have subsequently identified sensory channels and receptors that are specialized to detect specific sensory stimuli (12-14). Theories consistent with pattern theory, such as gate control $(1,15)$, argue against the existence of a specific pain labeled line and instead propose that pain sensation is generated by a summation of inputs from various primary sensory afferents and is subjected to modulation by descending inputs from the brain. Several recent reviews have pointed out that the coding of somatic sensation is involved in both specificity and complex mechanisms dependent on particular patterns of stimulation: there is no doubt about the existence of specific sensory labeled lines, but crosstalk among these lines generates and shapes somatosensory perception $(2,4,10,11,16,17)$. This synergistic view is referred to as population coding of somatic sensations $(16,18)$, which is essentially a modification of the original pattern theory. In this Review, we discuss new evidence supporting population coding; specifically, the coding of thermal sensation, and of pain versus itch.

\section{Population coding of cold, warm, and thermal pain: insight from human studies}

Soon after the discovery of cold and warm spots in the skin that suggested the existence of specific labeled lines, Thunberg and Alrutz independently discovered the "synthetic heat" phenomenon in 1896 (4). Thunberg found that stimulation of the skin with alternating cold and warm tubing (thermal grill) led to hot or burning

Conflict of interest: The author has declared that no conflict of interest exists. Citation for this article: J Clin Invest. 2010;120(11):3773-3778. doi:10.1172/JCI43426. sensation. Alrutz used a different method to concurrently activate both cold and warm spots, resulting in a similar paradoxical heat sensation $(4,6,19)$. Based on these observations, Alrutz proposed a pattern theory of thermoreception by stating that "heat is coded by a synthesis of warm fiber and cold fiber stimulation" (4).

From 1975 to 1990 , Mackenzie and several other investigators provided a key insight into the neural basis of thermal reception and perception (20-23). They found that a blockage of myelinated fibers (A-fibers) by ischemia or compression allows cold stimuli to activate non-myelinated C-fibers and to evoke heat or burning sensations. These findings suggest that (a) A-fibers responding to innocuous cold are necessary for cold sensation and (b) activation of "nociceptive" C-fibers by innocuous cold is able to evoke heat or burning sensation, but this sensation is normally masked by the activation of cold-sensitive A-fibers.

Craig and Bushnell then found two types of cold-sensitive neurons in the dorsal horn of the spinal cord (24). One responds specifically to cold temperatures, and such cells are referred to as COLD neurons. The other responds to heat, pinch, and cold, and these multimodal cells are referred to as HPC neurons. Interestingly, warming can suppress the activity of COLD, but not HPC, neurons (24). Together with the findings by Mackenzie and others, these observations suggest that the thermal grill illusion results from an antagonistic relationship between different labeled lines. First, coldsensitive A-fibers may connect with COLD neurons to evoke cold sensation (a cold labeled line), and activation of this labeled line will mask pain sensation evoked by the activation of cold-sensitive C-fibers (a heat or pain labeled line). A concurrent activation of warm fibers (a warm labeled line) on adjacent skin areas will centrally block the neural pathway activated by cold-sensitive A-fibers; as a result, cold-sensitive C-fibers are able to activate the pain-labeled line and create (paradoxically) a heat sensation (Figure 1). Indeed, imaging experiments by functional magnetic resonance imaging in humans show that the thermal grill is able to activate the anterior cingulate cortex that is normally activated by painful stimuli, whereas neither innocuous cold nor warm alone can activate this brain center (25).

Subsequent electrophysiological characterization of the thermal responsiveness of primary sensory afferents allowed Campero et al. to propose a more concrete population coding theory in explaining thermoreception and perception (Figure 2 and ref. 18 and references therein). They focused on Aס-cold fibers and thermosensitive C-fibers. Not included in the analysis was the first phase of pain, which is mediated by high-threshold myelinated nociceptors 


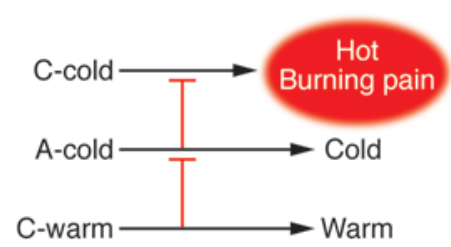

\section{Figure 1}

Crosstalk among warm, cold, and pain labeled lines. C-warm fibers mediate a neuronal pathway or labeled line for warmth sensation; A-cold fibers are part of the labeled line for innocuous cold sensation; and C-cold fibers respond to innocuous cold but evoke hot or burning pain sensation. The activity of C-cold fibers can be centrally inhibited by the activation of A-cold fibers, and the activity of A-cold fibers can be masked by the activation of $\mathrm{C}$-warm fibers. Simultaneous application of cold and warm stimuli by thermal grill allows C-cold fibers to activate the hot/burning labeled line, thereby leading to the thermal grill illusion.

$(8,26)$. Ad-cold fibers represent myelinated fibers that respond to innocuous cold temperatures but are inactivated by noxious cold $\left(<14^{\circ} \mathrm{C}\right)$. Thermosensitive $\mathrm{C}$-fibers in humans can be divided into multiple subtypes (ref. 18 and references therein). CMHC polymodal nociceptors respond to mechanical, heat, and noxious cold stimuli. C2 neurons belong to bimodal thermoreceptors that respond to innocuous and noxious cold $\left(0-30^{\circ} \mathrm{C}\right)$, but also to warm and/or hot temperatures $\left(38-48^{\circ} \mathrm{C}\right)$. C-warm neurons respond to warm temperatures and are inactivated by noxious cold and heat $(8,18)$. $\mathrm{CH}$ neurons respond specifically to noxious heat, and $\mathrm{CMH}$ neurons respond to both noxious mechanical stimuli and noxious heat. Each of these C-fiber subtypes could represent a mixed population due to distinct electrophysical properties and/or differential expression of ion channels and receptors. For example, different $\mathrm{CMH}$ fibers show distinct thresholds to radiant heat (8) and can be divided into rapid-adapting and slow-adapting subtypes (27). Based on the features of these thermosensitive C-fibers and Ad-cold fibers, Campero et al. proposed the population coding hypothesis for thermoreception and perception diagrammed in Figure 2 (18).

According to this model, when the skin is stimulated by noxious cold temperatures, both $\mathrm{C} 2$ fibers and $\mathrm{CMHC}$ fibers will be activated, leading to pain sensation (Figure 2B). Since cold stimuli evoke a hot or burning pain sensation following a blockage of A-fibers (20-23), the cold quality of cold pain may be either encoded by an unknown population of myelinated nociceptors that respond to noxious cold or encoded by a transient activation of A $\delta$-cold fibers (Figure 2B). Inactivation of A $\mathrm{d}$-cold fibers at noxious cold temperatures (18) also removes cold-induced pain inhibition, which in turn allows more $\mathrm{C} 2$ fibers to activate the pain pathway.

At innocuous cool temperatures $\left(>14^{\circ} \mathrm{C}\right)$, both $\mathrm{C} 2$ and $\mathrm{A} \delta$-cold fibers will be active. However, the activation of Ad-cold fibers can dominantly inhibit the neuronal pathway activated by the C2 fibers in higher brain centers, such as thalamic nuclei (28), leading to an innocuous cool sensation (Figure 2C). At warm temperatures $\left(30-38^{\circ} \mathrm{C}\right)$, only $\mathrm{C}$-warm fibers will be activated, leading to an innocuous warm sensation (Figure 2D). As temperatures increase $\left(>38^{\circ} \mathrm{C}\right)$, more and more $\mathrm{C} 2$ fibers will be activated and become dominant over C-warm fiber activity, leading to hot or burning sensation. Finally when temperatures reach noxious ranges, $\mathrm{C} 2, \mathrm{CH}, \mathrm{CMH}$, and possibly $\mathrm{CMHC}$ fibers will all be acti- vated, whereas $\mathrm{C}$-warm fiber activity will be inactivated, leading to a burning pain sensation (Figure 2F).

This population coding hypothesis can nicely explain several thermal paradoxes. For example, synthetic heat sensation created by concurrent activation of both cold and warm spots in the skin (thermal grill) can be explained by a blockage of the $A \delta$-cold fiber input by C-warm fibers, which in turn allows "unmasked" C2 fibers to evoke a burning sensation, as discussed above (Figure 2E). Green and colleagues reported that in some human subjects, innocuous cold stimuli alone are able to evoke a burning sensation, a phenomenon referred to "innocuous cold nociception," or ICN (4). It is possible that in those human subjects, the activity of the Ad-cold fibers might not be strong enough to mask all of $\mathrm{C} 2$ fiber activity.

The synthetic heat created by thermal grill is a form of spatial summation, following concurrent activation of cold and warm spots in the skin. Temporal summation of different thermal stimuli can also lead to paradoxical thermal sensation. For example, preheating the skin will allow cold stimuli to evoke paradoxical warmth or heat $(29,30)$. Other studies show that noxious stimuli, such as capsaicin injection in the skin, are able to suppress an inhibitory pathway in the spinal cord, thereby leading to central sensitization and the development of thermal and mechanical allodynia (31). Thus, skin preheating might block the inhibitory pathway normally activated by Ad-cold fibers, which might in turn allow innocuous cold to activate $\mathrm{C} 2$ fibers and evoke heat sensation.

It should be noted that the $\mathrm{C}$-fibers and $\mathrm{A} \delta$-cold fibers described in Figure 2 cannot entirely explain other paradoxical thermal sensations. For example, cold sensation can be evoked following the stimulation of a subset of cold spots with noxious heat (32), suggesting the existence of additional cold-sensing fibers that respond to both cold and heat stimuli. However, these fibers must connect with neuronal pathways involved in cold sensation, rather than heat/burning pain sensations.

\section{Molecular basis of thermoreception}

One great achievement in sensory biology was the identification of ion channels and receptors that respond to specific sensory stimuli $(13,14)$. In particular, the transient receptor potential (TRP) family of ion channels plays a critical role in thermoreception, as extensively reviewed by Basbaum, Julius, et al. (14). Here, we discuss how the expression and function of various TRP channels could be correlated with the thermal responsiveness of $\mathrm{C}$-fibers and A $\mathrm{A}$-cold fibers.

TRPM8 is a cold sensor, with an activation threshold in the innocuous cold range $\left(25 \sim 28^{\circ} \mathrm{C}\right)$, defined in heterologous systems $(33,34)$. This threshold is lower than that of many human C2 fibers $\left(>30^{\circ} \mathrm{C}\right)(18)$. However, in vivo cold sensitivity of sensory neurons can be modulated by other factors, such as the expression of two potassium channels, TREK1 and TRAAK (35-37). Genetic studies have established an essential role of TRPM8 in sensing innocuous cold (38-41). For example, mice lacking Trpm 8 fail to distinguish cold versus warm chambers (38-41). Thus, the responsiveness to innocuous cold by $\mathrm{A} \delta$-cold fibers is most likely encoded by the expression of TRPM8. Consistent with this finding, $14 \%-26 \%$ of TRPM8-expressing neurons in DRG and trigeminal ganglia are also A-fiber neurons (42), and cold responsiveness by A $\delta$-fibers and the cold-induced analgesic effect are virtually abolished in Trpm 8 mutant mice (39). TRPM8 is also partially involved in sensing noxious cold (38-41), suggesting that TRPM8 expression may confer C2-like fibers the ability to respond to both innocuous and noxious cold. 
A

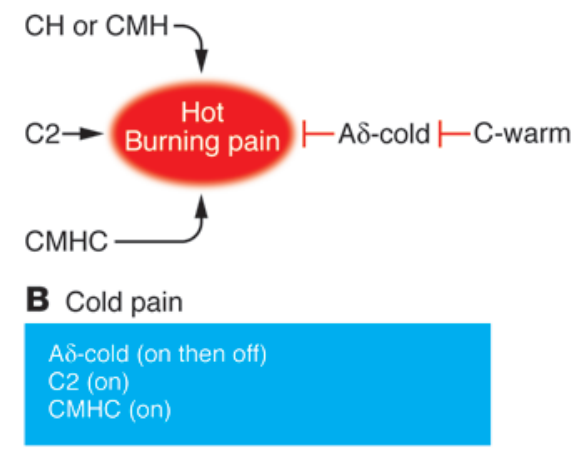

C Cool

A $\delta$-cold (on)

C2 (inhibited centrally by $A \delta$-cold)

D Warm

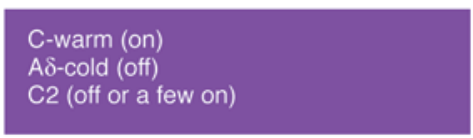

E Synthetic heat (thermal grill)

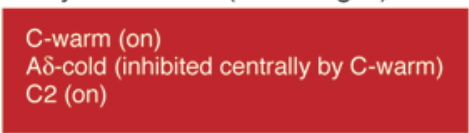

F Heat or burning pain (by heat stimuli)

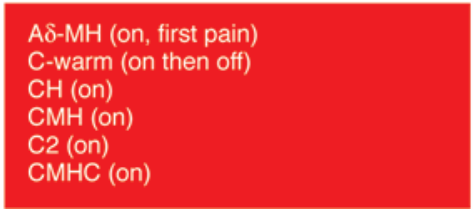

TRPA1 was initially proposed to sense noxious, but not innocuous, cold (43). However, the role of TRPA1 in sensing cold temperatures in somatic sensory neurons is still a matter of debate (9, 41, 44-47). Karashima et al. recently reported that TRPA1expressing neurons in the trigeminal ganglia are able to sense noxious cold (46), whereas several other studies failed to show cold sensitivity of these neurons $(48,49)$. This discrepancy might be reconciled by slow and weak activation of TRPA1 by cold; as a result, a short period of cold stimuli might fail to reveal TRPA1mediated cold sensitivity $(46,50)$. Notably, cold sensitivity is still detected in a subset of DRG neurons from mice that lack both Trpa1 and Trpm8, suggesting the existence of other cold-sensing channels or mechanisms (41) and also consistent with earlier electrophysiological studies (51). It should be noted that even if TRPA1-expressing neurons respond to noxious cold, injection of TRPA1 agonists would be expected to evoke burning pain, rather than cold pain, because TRPM8-dependent A $\delta$-cold fibers will not be activated, a prediction supported by human psychophysical studies (52). Under this hypothetical but still controversial condition, TRPA1 expression might confer CMHC neurons the ability to sense noxious, but not innocuous, cold.

TRPV1 responds to noxious heat, acid, toxins, and capsaicin (14). In mice, TRPV1 is preferentially associated with $\mathrm{CH}$ fibers and is necessary for these fibers to respond to noxious heat (53). Which

\section{Figure 2}

Population coding of thermal perceptions. The model is modified from ref. 18. (A) Functions and interaction of thermosensitive fibers. Note that $\mathrm{CH}, \mathrm{CMH}, \mathrm{C} 2$, and $\mathrm{CMHC}$ fibers all connect with neural pathways involved with hot or burning pain sensation. Activation of $A \delta$-cold fibers is able to suppress the sense of hot or burning pain. A $\delta$-cold fiber activity can be masked by the activation of C-warm fibers. (B-F) Fiber activity (within each rectangle) when a specific sensation (above each rectangle) is evoked. "on" means that the fiber is activated, and "off" means that the fiber is silent or inactivated. $\mathrm{CH}$, C-fibers responding only to noxious heat; $\mathrm{CMH}, \mathrm{C}$-fibers responding to noxious mechanical stimuli and heat; C2, C-fibers responding cold and warmth/heat; $\mathrm{CMHC}, \mathrm{C}$-fibers responding to noxious mechanical stimuli, heat, and noxious cold; A $\delta$-cold, A-fibers responding to innocuous cold; C-warm, C-fibers responding to warm temperatures; $\mathrm{A} \delta-\mathrm{MH}$, A-type fibers responding to mechanical stimuli and heat.

molecules could be responsible for the responsiveness of $\mathrm{C} 2$ fibers to warmth/heat at $38-48^{\circ} \mathrm{C}$ ? A portion of TRPM8-expressing neurons coexpress TRPV1 $(42,54)$, and up to $50 \%$ of DRG neurons that respond to menthol (an agonist of TRPM8) also respond to capsaicin (an agonist of TRPV1) $(33,55,56)$. Furthermore, a group of DRG neurons express a very high level of TRPV1 and respond to warm/heat temperatures at $38-48^{\circ} \mathrm{C}$, analogous to the thresholds for C2 fibers (57). Thus, it is possible that the coexpression of TRPM8 and TRPV1 might confer C2 fibers the capacity to respond to both innocuous cold and to warmth/heat. TRPV3 is another channel responding to warm and hot temperatures (58-60). Interestingly, TRPV3 is expressed in both DRG neurons and keratinocytes in humans, but only in keratinocytes in mice (58). In response to warmth and heat, keratinocytes may release chemicals such as UTP and ATP, which in turn activate P2X and P2Y receptors in skin nerve terminals (58-61). For example, P2Y2 is a receptor of UTP, and its expression in mouse DRG neurons is required for proper heat sensation (62). Thus, it is possible that TRPV3 expression in DRG neurons and/or in keratinocytes could be directly or indirectly linked to $\mathrm{C} 2$ fibers in sensing warmth/heat.

In rats and humans, $\mathrm{CMH}$ neurons respond to capsaicin, suggesting that expression of TRPV1 in these neurons could confer the ability to respond to noxious heat (63). The situation is, however, quite different in mice, in which a large subset of $\mathrm{CMH}$ neurons does not respond to capsaicin due to a lack of TRPV1 expression (53). Most CMH neurons in mice can be marked by the expression of the $G$ protein-coupled receptor Mrgprd, and these neurons coexpressed P2X3 (53, 64-66). It was proposed that heat responsiveness of some $\mathrm{CMH}$ neurons in mice might be indirectly mediated by chemicals released from keratinocytes (60).

By summarizing the expression and functions of thermosensitive TRP channels, we can draw the following conclusions. First, a sensory receptor (such as TRPM8) that responds to a specific stimulus (innocuous cold) can be associated with distinct sensory modalities (such as A $\mathrm{d}$-cold fibers and C2 pain fibers). Second, a given sensory fiber (such as a C2 fiber) can express multiple receptors (TRPM8 and TRPV1); as a result, this fiber becomes polymodal (responding to both innocuous cold and noxious heat), even though activation of this fiber is invariably associated with a specific somatic sensation (burning pain in the case of $\mathrm{C} 2$ fibers). Thus, the responsiveness of an isolated sensory fiber to a particular stimulus cannot predict what kind of sensory modality it is associated with. The fact that a given stimulus can often activate multiple labeled lines also suggests that the emergence of a specific somatic sensation is likely achieved 


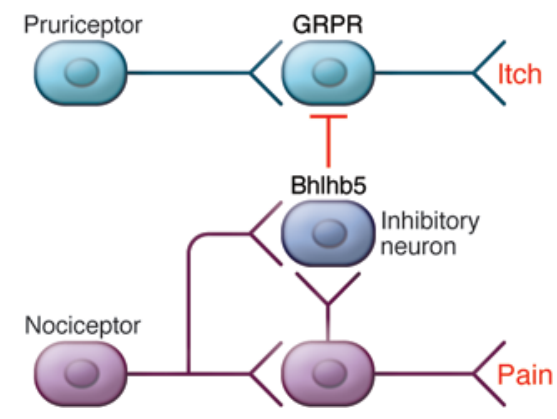

Figure 3

Population coding of pain versus itch. Pain and itch are processed along two different labeled lines. Activation of pain-sensing neurons may activate Bhlhb5-expressing inhibitory neurons in the spinal cord, which in turn suppress itch-sensing GRPR-expressing spinal neurons.

through crosstalk among different sensory labeled lines, as we have discussed above (Figures 1 and 2).

\section{The coding of pain versus itch}

Itch and pain represent two distinct sensations and evoke withdrawal and scratching responses, respectively $(11,67)$. A series of studies have supported the existence of specific labeled lines in processing itch. Von Frey first recognized specific skin spots whose activation evokes itch (68). Using the microneurographic technique, Schmelz et al. first identified histamine-sensitive mechano-insensitive primary afferents whose activation is correlated with itch sensation in humans (69). More recently, it was found that sensory neurons expressing the GPCR MrgprA3, representing 4\%-5\% of dorsal root ganglion (DRG) neurons (70), are required to sense itch evoked by chloroquine, but are dispensable for pain (71). Furthermore, cell ablation experiments in mice show that spinal cord neurons expressing the gastrin-releasing peptide receptor (GRPR) are required to sense itch, but not pain, strongly suggesting separate neuronal pathways or labeled lines in processing itch versus pain $(72,73)$.

Other studies, however, show that itch-sensing neurons (pruriceptors) can respond to pain-inducing (algogenic) stimuli. For example, pruriceptors that respond to histamine, serotonin, trypsin, and chloroquine also respond to capsaicin (74-80). In other words, capsaicin-responsive DRG neurons can be divided into pain-sensing and itch-sensing subpopulations. Similarly, two pruritic agents, cowhage spicules and agonists of the proteinase-activated receptor 2 (PAR-2), are able to activate most $\mathrm{CMH}$ polymodal nociceptors, which respond to heat and noxious mechanical stimuli $(81,82)$. These findings pose a dilemma in understanding the coding of pain versus itch. For example, subcutaneous injection of capsaicin evokes pain, even though both pain-sensing and itchsensing nociceptors are supposed to be activated (75-77, 79, 80). To explain this dilemma, several theories have been proposed.

The "spatial contrast" theory proposes that itch is encoded when a minority of nociceptive fibers are activated in a receptive field, and pain is encoded when a large number of nociceptor fibers are activated $(11,82-84)$. This theory argues that pain and itch can be coded in the absence of pain-specific and itch-specific labeled lines (82). However, this theory appears to conflict with increasing evidence supporting the existence of itch-specific primary and relay sensory neurons $(69,71-73$, $85)$. For example, it is very difficult to explain why GRPR-expressing spinal neurons are dedicated to the transmission of itch (73).
Carstens and colleagues proposed the population coding hypothesis to account for the apparent contradiction $(16,86)$, which is essentially the same as the selectivity hypothesis of itch $(17,87)$. This hypothesis highlights two features. First, itch and pain are processed along distinct neural circuits or labeled lines, as supported by the existence of itch-specific primary and relay neurons (69, $71,73)$. Second, pruriceptors can respond to an allogeneic stimulus, but activation of a larger number of pain-specific fibers can dominantly mask itch $(16,86)$. Indeed, an antagonistic relationship between pain and itch has long been recognized (11,88-91). Over 80 years ago, Lewis found that itch evoked by histamine injection can be suppressed by electric stimuli (88). A range of other painful stimuli can also suppress itch $(89,92)$. Mechanistically, scratching, a painful stimulus, can directly silence the firing of histamine-sensitive neurons in the spinal cord (91). Conversely, an inhibition of pain can enhance histamine-induced itch (90), and itch is a common side effect of analgesic treatment with opioids (11).

Could the population coding hypothesis explain the following paradox: while subcutaneous capsaicin injection evokes "pure" pain, delivery of capsaicin into the skin epidermis by a single cowhage spicule evokes itch and a nociceptive sensation (79)? As discussed above, capsaicin-responsive neurons can be divided into pain-sensing and itch-sensing subpopulations (74-80). It was accordingly postulated that capsaicin-responsive fibers in the skin epidermis might be enriched for itch-sensing fibers, whereas those in the dermis or deeper tissues might be enriched for pain-sensing fibers (79). Indeed, Mrgpra3-expressing neurons respond to capsaicin and histamine and are involved in itch evoked by chloroquine (71); moreover, genetic axonal marking shows that neurons expressing the Mrgpr family of GPCRs tend to project into the skin epidermis $(65,93)$. Thus, according to the population coding hypothesis, epidermal capsaicin delivery may preferentially activate pruriceptors and/or only generate a weak pain or nociceptive sensation that is insufficient to mask itch. However, it has not yet been tested whether itch evoked by epidermal capsaicin delivery could be indirectly caused by an activation of TRPV1 in keratinocytes (94).

There is an unsolved dilemma in explaining itch evoked by cowhage or by PAR- 2 agonists. These two pruritic agents are able to evoke histamine-independent itch (95-98) but surprisingly activate a majority of CMH polymodal nociceptors $(81,82)$. In fact, PAR-2 is expressed in nearly $90 \%$ of TRPV1-expressing neurons $(99,100)$, and PAR-2 agonists can sensitize TRPV1 and cause inflammatory hyperalgesia (99-102). How then could cowhage and PAR-2 agonists evoke itch? Several possibilities have been suggested $(81,82)$. First, in primates, cowhage spicules evoke bursting discharge of $\mathrm{CMH}$ nociceptors, whereas noxious heat at $53^{\circ} \mathrm{C}$ induces nonbursting discharge $(27,81)$. Accordingly, it was postulated that pain and itch might be encoded by distinct firing patterns of C-fibers (81). However, this theory was disputed by human studies showing no correlation between firing patterns and the senses of pain versus itch (82, 103). Second, CMH neurons can be divided into quickly adapting (QC) and slowly adapting (SC) subtypes (27). In primates, QC fibers have a more robust cowhage response than SC fibers, raising the possibility that QC fibers might be enriched for pruriceptors, whereas SC fibers might be enriched for pain-sensing nociceptors (81). In other words, itch sensation emerges following strong activation of QC itch fibers and weak activation of SC pain fibers, which is not inconsistent with the population coding hypothesis. Third, cowhage itch may be mediated by a coactivation of A-fibers and CMH fibers $(81,82,92)$. Interestingly, while activation of $\mathrm{CMH}$ fibers by nox- 
ious heat generates pain, mechanical stimuli at thresholds that can activate $\mathrm{CMH}$ fibers fail to generate pain, likely due to a concurrent activation of low-threshold $A \beta$-fibers that can inhibit pain (104). By analogy, itch might emerge following an activation of itch-sensing A-fibers that might centrally mask pain-sensing $\mathrm{CMH}$ fiber activity, which is further analogous to cold sensation following concurrent activation of A $\delta$-cold fibers and C2 pain fibers (Figures 1 and 2). Such crosstalk among different labeled lines would again be consistent with the population coding hypothesis.

Thus, a summary of the current literature appears to support the population coding hypothesis that emphasizes both the existence of itch-specific and pain-specific neural circuits and an antagonistic relationship between pain and itch. How could pain suppress itch? It was postulated that pain fibers may connect with spinal inhibitory neurons to mask itch (Figure 3). For example, intradermal capsaicin injection, which causes pain, is able to activate a large subset of inhibitory neurons in the dorsal horn of the spinal cord $(31,105)$. A more recent study shows that a group of spinal cord inhibitory neurons, whose development is dependent on a transcription factor called Bhlhb5, is involved in itch suppression (106). Developmental impairment of these inhibitory neurons leads to the sensitization of multiple itch pathways and the development of excessive scratching and severe skin lesions (106). It is attractive to postulate that pain fibers may connect with Bhlhb5dependent inhibitory neurons to suppress itch (Figure 3).

\section{Concluding remarks}

The coding of somatic sensory information might be best explained by the population coding hypothesis. This hypothesis is composed of two components. First, the senses of pain, itch, and temperature are in part selectively processed along specific labeled lines. Second, these labeled lines are not independent. Rather, crosstalk (often antagonistic interaction) between distinct labeled lines in the spinal cord or in the brain is involved in the emergence of a specific somatic sensation, particularly when multiple labeled lines respond to the same stimulus. A critical feature of this hypothesis is that responsiveness of individual nerve fibers to a particular sensory stimulus does not necessarily correlate with the perception of that stimulus. For example, coldsensitive $\mathrm{C} 2$ pain fibers are involved in burning pain sensation, and heat-sensitive fibers can be involved in sensing cold or itch. Clearly, one frontier in sensory biology studies will be to illustrate how exactly these sensory labeled lines meet and talk in the dorsal spinal cord and in the brain.

\section{Acknowledgments}

The author thanks Joachim Scholz for critically reading the manuscript as well as his laboratory colleagues, particularly FuChia Yang and Taralyn Tan, for reading and discussions. Q. Ma is supported by NIH grants from the National Institute of Dental and Craniofacial Research (NIDCR; R01DE018025) and the National Institute of Neurological Disorders and Stroke (NINDS; P01NS047572 and R01NS047710).

Address correspondence to: Qiufu Ma, Dana-Farber Cancer Institute and Department of Neurobiology, Harvard Medical School, 1 Jimmy Fund Way, Boston, Massachusetts 02115, USA. Phone: 617.632.4594; Fax: 617.632.4595; E-mail: Qiufu_Ma@dfci.harvard.edu.
1. Melzack R, Wall PD. Pain mechanisms: a new theory. Science. 1965;150(699):971-979.

2. Craig AD. Pain mechanisms: labeled lines versus convergence in central processing. Annu Rev Neurosci. 2003;26:1-30.

3. Perl ER. Getting a line on pain: is it mediated by dedicated pathways? Nat Neurosci. 1998;1(3):177-178.

4. Green BG. Temperature perception and nociception. J Neurobiol. 2004;61(1):13-29.

5. Perl ER. Ideas about pain, a historical view. Nat Rev Neurosci. 2007;8(1):71-80.

6. Norrsell U, Finger S, Lajonchere C. Cutaneous sensory spots and the "law of specific nerve energies": history and development of ideas. Brain Res Bull. 1999;48(5):457-465

7. Torebjörk HE, Schady W, Ochoa J. Sensory correlates of somatic afferent fibre activation. Hum Neurobiol. 1984;3(1):15-20.

8. Handwerker HO, Kobal G. Psychophysiology of experimentally induced pain. Physiol Rev. 1993; 73(3):639-671.

9. Belmonte C, Brock JA, Viana F. Converting cold into pain. Exp Brain Res. 2009;196(1):13-30.

10. Campero M, Bostock H. Unmyelinated afferents in human skin and their responsiveness to low temperature. Neurosci Lett. 2010;470(3):188-192.

11. Schmelz M. Itch and pain. Neurosci Biobehav Rev. 2010;34(2):171-176.

12. Woolf CJ, Ma Q. Nociceptors-noxious stimulus detectors. Neuron. 2007;55(3):353-364.

13. Foulkes T, Wood JN. Pain genes. PLoS Genetics. 2008;4(7):e1000086.

14. Basbaum AI, Bautista DM, Scherrer G, Julius D. Cellular and molecular mechanisms of pain. Cell. 2009;139(2):267-284

15. Wall PD. The gate control theory of pain mechanisms. A re-examination and re-statement. Brain. 1978; 101(1):1-18.

16. Wood GJ, Akiyama T, Carstens E, Oaklander AL,
Yosipovitch G. An insatiable itch. J Pain. 2009; 10(8):792-797.

17. Handwerker HO. Microneurography of pruritus. Neurosci Lett. 2010;470(3):193-196.

18. Campero M, Baumann TK, Bostock H, Ochoa JL. Human cutaneous C fibres activated by cooling, heating and menthol. J Physiol. 2009; 587(pt 23):5633-5652.

19. Alrutz S. On the temperature senses: II. The sensation of 'hot'. Mind. 1898;7:140-144.

20. Mackenzie RA, Burke D, Skuse NF, Lethlean AK. Fibre function and perception during cutaneous nerve block. J Neurol Neurosurg Psychiatry. 1975;38(9):865-873.

21. Fruhstorfer $H$. Thermal sensibility changes during ischemic nerve block. Pain. 1984;20(4):355-361.

22. Wahren LK, Torebjörk E, Jörum E. Central suppression of cold-induced $\mathrm{C}$ fibre pain by myelinated fibre input. Pain. 1989;38(3):313-319.

23. Yarnitsky D, Ochoa JL. Release of cold-induced burning pain by block of cold-specific afferent input. Brain. 1990;113(pt 4):893-902.

24. Craig AD, Bushnell MC. The thermal grill illusion: unmasking the burn of cold pain. Science. 1994;265(5169):252-255.

25. Craig AD, Reiman EM, Evans A, Bushnell MC. Functional imaging of an illusion of pain. Nature. 1996;384(6606):258-260.

26. Price DD, Hu JW, Dubner R, Gracely RH. Peripheral suppression of first pain and central summation of second pain evoked by noxious heat pulses. Pain. 1977;3(1):57-68.

27. Meyer RA, Campbell JN. Evidence for two distinct classes of unmyelinated nociceptive afferents in monkey. Brain Res. 1981;224(1):149-152.

28. Defrin R, Benstein-Sheraizin A, Bezalel A, Mantzur O, Arendt-Nielsen L. The spatial characteristics of the painful thermal grill illusion. Pain. 2008;138(3):577-586.
29. Jenkins WL, Karr AC. Paradoxical warmth: a sufficient condition for its arousal. Am J Psychol. 1957;70(4):640-641.

30. Hämäläinen H, Vartiainen M, Karvanen L, Järvilehto T. Paradoxical heat sensations during moderate cooling of the skin. Brain Res. 1982;251(1):77-81.

31. Zhou HY, Zhang HM, Chen SR, Pan H. Increased nociceptive input rapidly modulates spinal GABAergic transmission through endogenously released glutamate. J Neurophysiol. 2007;97(1):871-882.

32. Dodt E, Zotterman Y. The discharge of specific cold fibres at high temperatures; the paradoxical cold. Acta Physiol Scand. 1952;26(4):358-365.

33. McKemy DD, Neuhausser WM, Julius D. Identification of a cold receptor reveals a general role for TRP channels in thermosensation. Nature. 2002; 416(6876):52-58.

34. Peier AM, et al. A TRP channel that senses cold stimuli and menthol. Cell. 2002;108(5):705-715.

35. Alloui A, et al. TREK-1, a $\mathrm{K}+$ channel involved in polymodal pain perception. EMBO J. 2006; 25(11):2368-2376.

36. Madrid R, de la Peña E, Donovan-Rodriguez T, Belmonte C, Viana F. Variable threshold of trigeminal cold-thermosensitive neurons is determined by a balance between TRPM 8 and Kv1 potassium channels. J Neurosci. 2009;29(10):3120-3131.

37. Noël J, et al. The mechano-activated $\mathrm{K}+$ channels TRAAK and TREK- 1 control both warm and cold perception. EMBO J. 2009;28(9):1308-1318.

38. Colburn RW, et al. Attenuated cold sensitivity in TRPM8 null mice. Neuron. 2007;54(3):379-386.

39. Bautista DM, et al. The menthol receptor TRPM8 is the principal detector of environmental cold. Nature. 2007;448(7150):204-208.

40. Dhaka A, Murray AN, Mathur J, Earley TJ, Petrus MJ, Patapoutian A. TRPM8 is required for cold sensation in mice.[see comment]. Neuron. 2007;54(3):371-378.

41. Knowlton WM, Bifolck-Fisher A, Bautista DM, 
McKemy DD. TRPM8, but not TRPA1, is required for neural and behavioral responses to acute noxious cold temperatures and cold-mimetics in vivo. Pain. 2010;150(2):340-350.

42. Takashima Y, Daniels RL, Knowlton W, Teng J, Liman ER, McKemy DD. Diversity in the neural circuitry of cold sensing revealed by genetic axonal labeling of transient receptor potential melastatin 8 neurons. J NeuroSci. 2007;27(51):14147-14157.

43. Story GM, et al. ANKTM1, a TRP-like channel expressed in nociceptive neurons, is activated by cold temperatures. Cell. 2003;112(6):819-829.

44. Bautista DM, et al. TRPA1 mediates the inflammatory actions of environmental irritants and proalgesic agents. Cell. 2006;124(6):1269-1282.

45. Kwan KY, et al. TRPA1 contributes to cold, mechani$\mathrm{cal}$, and chemical nociception but is not essential for hair-cell transduction. Neuron. 2006;50(2):277-289.

46. Karashima Y, et al. TRPA1 acts as a cold sensor in vitro and in vivo. Proc Natl Acad Sci U S A. 2009; 106(4):1273-1278

47. Dunham JP, Leith JL, Lumb BM, Donaldson LF. Transient receptor potential channel A1 and noxious cold responses in rat cutaneous nociceptors. NeuroScience. 2010;165(4):1412-1419.

48. Jordt SE, et al. Mustard oils and cannabinoids excite sensory nerve fibres through the TRP channel ANKTM1. Nature. 2004;427(6971):260-265.

49. Fajardo O, Meseguer V, Belmonte C, Viana F. TRPA1 channels mediate cold temperature sensing in mammalian vagal sensory neurons: pharmacological and genetic evidence. J Neurosci. 2008;28(31):7863-7875.

50. Kwan KY, Corey DP. Burning cold: involvement of TRPA1 in noxious cold sensation. J Gen Physiol. 2009;133(3):251-256

51. Munns C, AlQatari M, Koltzenburg M. Many cold sensitive peripheral neurons of the mouse do not express TRPM8 or TRPA1. Cell Calcium. 2007;41(1):41.

52. Namer B, Seifert F, Handwerker HO, Maihöfner C. TRPA 1 and TRPM8 activation in humans: effects of cinnamaldehyde and menthol. Neuroreport. 2005; 16(9):955-959.

53. Lawson JJ, McIlwrath SL, Woodbury CJ, Davis BM, Koerber HR. TRPV1 unlike TRPV2 is restricted to a subset of mechanically insensitive cutaneous nociceptors responding to heat. J Pain. 2008;9(4):298-308.

54. Dhaka A, Earley TJ, Watson J, Patapoutian A. Visualizing cold spots: TRPM8-expressing sensory neurons and their projections. J Neurosci. 2008;28(3):566-575.

55. Viana F, de la Peña E, Belmonte C. Specificity of cold thermotransduction is determined by differential ionic channel expression. Nat Neurosci. 2002; 5(3):254-260.

56. Hjerling-Leffler J, Alqatari M, Ernfors P, Koltzenburg M. Emergence of functional sensory subtypes as defined by transient receptor potential channel expression. J Neurosci. 2007;27(10):2435-2443.

57. Kiasalari Z, Salehi I, Zhong Y, McMahon SB, Michael-Titus AT, Michael GJ. Identification of perineal sensory neurons activated by innocuous heat. J Comp Neurol. 2010;518(2):137-162.

58. Dhaka A, Viswanath V, Patapoutian A. Trp ion channels and temperature sensation. Annu Rev NeuroSci. 2006;29:135-161.

59. Lumpkin EA, Caterina MJ. Mechanisms of sensory transduction in the skin. Nature. 2007; 445(7130):858-865

60. Dussor G, Koerber HR, Oaklander AL, Rice FL, Molliver DC. Nucleotide signaling and cutaneous mechanisms of pain transduction. Brain Res Rev. 2009;60(1):24-35.

61. Mandadi S, et al. TRPV3 in keratinocytes transmits temperature information to sensory neurons via ATP. Pflugers Arch. 2009;458(6):1093-1102.

62. Malin SA, Davis BM, Koerber HR, Reynolds IJ, Albers KM, Molliver DC. Thermal nociception and TRPV1 function are attenuated in mice lacking the nucleotide receptor P2Y2. Pain. 2008;138(3):484-496.

63 . Handwerker HO. What is a polymodal nociceptor?
J Pain. 2008;9(4):309-310.

64. Dong X, Han S, Zylka MJ, Simon MI, Anderson DJ. A diverse family of GPCRs expressed in specific subsets of nociceptive sensory neurons. Cell. 2001; 106(5):619-632.

65. Zylka MJ, Rice FL, Anderson DJ. Topographically distinct epidermal nociceptive circuits revealed by axonal tracers targeted to Mrgprd. Neuron. 2005;45(1):17-25.

66. Rau KK, et al. Mrgprd enhances excitability in specific populations of cutaneous murine polymodal nociceptors. J Neurosci. 2009;29(26):8612-8619.

67. Ikoma A, Steinhoff M, Ständer S, Yosipovitch G, Schmelz M. The neurobiology of itch. Nat Rev New rosci. 2006;7(7):535-547.

68. von Frey M. Zur physiologie der juckempfindug. Arc Néerl Phyiol. 1922;7:142-145.

69. Schmelz M, Schmidt R, Bickel A, Handwerker HO, Torebjörk HE. Specific C-receptors for itch in human skin. J Neurosci. 1997;17(20):8003-8008.

70. Liu Y, et al. Mechanisms of compartmentalized expression of Mrg class G-protein-coupled sensory receptors. J Neurosci. 2008;28(1):125-132.

71. Liu Q, et al. Sensory neuron-specific GPCR Mrgprs are itch receptors mediating chloroquine-induced pruritus. Cell. 2009;139(7):1353-1365.

72. Sun YG, Chen ZF. A gastrin-releasing peptide receptor mediates the itch sensation in the spinal cord. Nature. 2007;448(7154):700-703.

73. Sun YG, Zhao ZQ, Meng XL, Yin J, Liu XY, Chen ZF. Cellular basis of itch sensation. Science. 2009 325(5947):1531-1534.

74. Green BG, Shaffer GS. The sensory response to capsaicin during repeated topical exposures: differential effects on sensations of itching and pungency. Pain. 1993;53(3):323-334.

75. Schmelz M, Schmidt R, Weidner C, Hilliges M, Torebjork HE, Handwerker HO. Chemical response pattern of different classes of C-nociceptors to pruritogens and algogens. J Neurophysiol. 2003;89(5):2441-2448.

76. Shim WS, et al. TRPV1 mediates histamine-induced itching via the activation of phospholipase A2 and 12-lipoxygenase. J Neurosci. 2007;27(9):2331-2337.

77. Costa R, et al. Evidence for the role of neurogenic inflammation components in trypsin-elicited scratching behaviour in mice. BrJ Pharmacol. 2008; 154(5):1094-1103.

78. Shim WS, Oh U. Histamine-induced itch and its relationship with pain. Mol Pain. 2008;4:29.

79. Shimada SG, LaMotte RH. Behavioral differentiation between itch and pain in mouse. Pain. 2008; 139(3):681-687.

80. Imamachi $\mathrm{N}$, et al. TRPV1-expressing primary afferents generate behavioral responses to pruritogens via multiple mechanisms. Proc Natl Acad Sci US A 2009;106(27):11330-11335.

81. Johanek LM, et al. A role for polymodal C-fiber afferents in nonhistaminergic itch. J Neurosci. 2008 28(30):7659-7669.

82. Namer B, Carr R, Johanek LM, Schmelz M, Handwerker HO, Ringkamp M. Separate peripheral pathways for pruritus in man. J Neurophysiol. 2008; 100(4):2062-2069.

83. Sikand P, Shimada SG, Green BG, LaMotte RH Similar itch and nociceptive sensations evoked by punctate cutaneous application of capsaicin, histamine and cowhage. Pain. 2009;144(1-2):66-75.

84. LaMotte RH, Shimada SG, Green BG, Zelterman D. Pruritic and nociceptive sensations and dysesthesias from a spicule of cowhage. J Neurophysiol. 2009; 101(3):1430-1443.

85. Andrew D, Craig AD. Spinothalamic lamina I neurons selectively sensitive to histamine: a central neural pathway for itch. Nat Neurosci. 2001;4(1):72-77.

86. Akiyama T, Merrill AW, Carstens MI, Carstens E. Activation of superficial dorsal horn neurons in the mouse by a PAR-2 agonist and 5-HT: potential role in itch. J Neurosci. 2009;29(20):6691-6699.

87. McMahon SB, Koltzenburg M. Itching for an expla- nation. Trends Neurosci. 1992;15(12):497-501.

88. Lewis T, Grant RT, Marvin HM. Vascular rections of skin to injury. Part X. The intervention of a chemical stimulus illustrated especially by the flare. Heart. 1929;14:139-160.

89. Ward L, Wright E, McMahon SB. A comparison of the effects of noxious and innocuous counterstimuli on experimentally induced itch and pain. Pain. 1996;64(1):129-138.

90. Atanassoff PG, Brull SJ, Zhang J, Greenquist K, Silverman DG, Lamotte RH. Enhancement of experimental pruritus and mechanically evoked dysesthesiae with local anesthesia. Somatosens Mot Res. 1999;16(4):291-298

91. Davidson S, Zhang X, Khasabov SG, Simone DA, Giesler GJJ. Relief of itch by scratching: statedependent inhibition of primate spinothalamic tract neurons. Nat Neurosci. 2009;12(5):544-546.

92. Graham DT, Goodell H, Wolff HG. Neural mechanisms involved in itch, itchy skin, and tickle sensations. J Clin Invest. 1951;30(1):37-49.

93. Liu Q, Vrontou S, Rice FL, Zylka MJ, Dong X, Anderson DJ. Molecular genetic visualization of a rare subset of unmyelinated sensory neurons that may detect gentle touch. Nat Neurosci. 2007;10(8):946-948.

94. Southall MD, Li T, Gharibova LS, Pei Y, Nicol GD, Travers JB. Activation of epidermal vanilloid receptor-1 induces release of proinflammatory mediators in human keratinocytes. J Pharmacol Exp Ther. 2003; 304(1):217-222.

95. Shimada SG, Shimada KA, Collins JG. Scratching behavior in mice induced by the proteinase-activated receptor-2 agonist, SLIGRL-NH2. EurJ Pharmacol. 2006;530(3):281-283.

96. Davidson S, Zhang X, Yoon CH, Khasabov SG, Simone DA, Giesler GJJ. The itch-producing agents histamine and cowhage activate separate populations of primate spinothalamic tract neurons. J Neurosci. 2007;27(37):10007-10014.

97. Johanek LM, et al. Psychophysical and physiological evidence for parallel afferent pathways mediating the sensation of itch. J Neurosci. 2007;27(28):7490-7497.

98. Tsujii K, Andoh T, Lee JB, Kuraishi Y. Activation of proteinase-activated receptors induces itch-associated response through histamine-dependent and independent pathways in mice.J Pharmacol Sci. 2008; 108(3):385-388.

99. Dai Y, et al. Proteinase-activated receptor 2-mediated potentiation of transient receptor potential vanilloid subfamily 1 activity reveals a mechanism for proteinase-induced inflammatory pain. J Neurosci. 2004;24(18):4293-4299.

100.Amadesi S, et al. Protease-activated receptor 2 sensitizes the capsaicin receptor transient receptor potential vanilloid receptor 1 to induce hyperalgesia. J Neurosci. 2004;24(18):4300-4312.

101.Linley JE, Rose K, Patil M, Robertson B, Akopian AN, Gamper N. Inhibition of M current in sensory neurons by exogenous proteases: a signaling pathway mediating inflammatory nociception. J Neurosci. 2008;28(44):11240-11249.

102. Paszcuk AF, et al. Mechanisms underlying the nociceptive and inflammatory responses induced by trypsin in the mouse paw. Eur J Pharmacol. 2008; 581(1-2):204-215.

103. Tuckett RP. Itch evoked by electrical stimulation of the skin. J Invest Dermatol. 1982;79(6):368-373.

104.Van Hees J, Gybels J. C nociceptor activity in human nerve during painful and non painful skin stimulation. J Neurol Neurosurg Psychiatry. 1981; 44(7):600-607.

105.Zou X, Lin Q, Willis WD. The effects of sympathectomy on capsaicin-evoked fos expression of spinal dorsal horn GABAergic neurons. Brain Res. 2002;958(2):322-329.

106. Ross SE, et al. Loss of inhibitory interneurons in the dorsal spinal cord and elevated itch in Bhlhb5 mutant mice. Neuron. 2010;65(6):886-898. 